\title{
Immature Monocyte Count
}

National Cancer Institute

\section{Source}

National Cancer Institute. Immature Monocyte Count. NCI Thesaurus. Code C96676.

The determination of the amount of immature monocytes present in a sample. 